\title{
Criopirinopatías: ¿qué son?, ¿cómo detectarlas? y ¿cuál es el enfoque de su tratamiento?
}

Cryopyrinopathies: ¿what are they, how to detect them and what is the focus of their treatment?

\author{
Maribel Gallego $^{1 \star}$, Catalina Jaramillo ${ }^{1 \star}$, Jaime Sierra ${ }^{1 \star}$, Margarita María Velásquez ${ }^{2}$ \\ 1. Médico, dermatólogo, Facultad de Medicina, Universidad de Antioquia, Medellín, Colombia \\ 2. Médica dermatóloga, doctora en Ciencias Básicas Biomédicas con énfasis en Inmunología; profesora, Sección de Dermatología, \\ Centro de Investigaciones Dermatológicas CIDERM, Facultad de Medicina, Universidad de Antioquia, Medellín, Colombia \\ *Los tres autores contribuyeron por igual en la elaboración del manuscrito.
}

\section{RESUMEN}

Los síndromes periódicos asociados con criopirinas (Cryopyrin Associated Periodic Syndromes, CAPS), o criopirinopatías, son enfermedades raras que hacen parte de los síndromes autoinflamatorios, caracterizados por episodios de fiebre recurrente e inflamación sin etiología autoinmunitaria, neoplásica ni infecciosa. Entre estos síndromes, los CAPS incluyen tres entidades: el síndrome autoinflamatorio familiar por frío (Familial Cold Autoinflammatory Syndrome, FCAS), el síndrome de Muckle-Wells y la enfermedad multisistémica inflamatoria de inicio neonatal (Neonatal Onset Multisystem Inflammatory Disease, NOMID), también conocida como síndrome articular, cutáneo y neurológico crónico infantil (Chronic Infantile Neurological Cutaneous and Articular (CINCA) syndrome).

Se han identificado mutaciones en el gen $N L R P_{3}$ como etiología de estos síndromes, con un patrón de herencia autosómico dominante en la mayoría de los casos. El diagnóstico suele hacerse por sus manifestaciones clínicas, con apoyo de la biopsia de piel, y se confirma con el estudio genético. Hasta la fecha, el tratamiento basado en el bloqueo de la IL-1 $\beta$, ha mostrado una mejoría satisfactoria en la mayoría de los pacientes.

PAlabRas CLAVE: síndromes periódicos asociados con criopirinas, síndrome CINCA, síndrome articular y cutáneo neurológico infantil crónico, criopirinopatía, síndrome autoinflamatorio familiar por frío, urticaria familiar por frío, enfermedad inflamatoria multisistémica de inicio en la infancia (IOMID), síndrome de Muckle-Wells, enfermedad inflamatoria multisistémica de inicio en el periodo neonatal (NOMID), proteína con dominio pirina 3 de la familia NLR

\section{SUMMARY}

The cryopyrin associated periodic syndromes (CAPS) are rare diseases that are part of the autoinflammatory syndromes. CAPS are characterized by recurrent episodes of fever and inflammation without autoimmune, neoplastic or infectious etiology. CAPS include three entities; these are familial cold autoinflammatory syndrome (FCAS), Muckle-Wells syndrome (MWS) and neonatal
Correspondencia:

Margarita María Velásquez

Email:

mmvelasquez@yahoo.com

Recibido: $11 / 10 / 16$

Aceptado: 26/06/18

Conflictos de interés:

No se reportan conflictos de interés.

Financiación:

Ninguna. 
onset multi-system inflammatory disease (NOMID). Mutations in the NLRP3 gene have been identified as the etiology of these syndromes, with autosomal dominant inheritance in most cases. Diagnosis is usually made with the clinical history, supported by the skin biopsy and confirmed in the genetic study. Treatment based on blocking IL-1 $\beta$, to date has shown satisfactory response in most patients.

KEY WORDS: Cryopyrin-associated periodic syndromes, NLR family, pyrin domain-containing 3 protein

\section{INTRODUCCIÓN}

Los síndromes periódicos asociados con criopirinas (Cryopyrin Associated Periodic Syndromes, CAPS), pertenecen a las llamadas enfermedades autoinflamatorias, causadas por mutaciones en genes que codifican moléculas involucradas en la regulación de la reacción inmunitaria innata ${ }^{(1)}$. Se les ha denominado autoinflamatorias, ya que no se relacionan con marcadores de autoinmunidad, como autoanticuerpos ni linfocitos $\mathrm{T}$ o B autorreactivos ${ }^{(2)}$.

El concepto de autoinflamación fue inicialmente propuesto por Kastner en 1999, después de encontrar que una serie de mutaciones en el receptor para el factor de necrosis tumoral (TNF) era la causa de un síndrome asociado con fiebre periódica, llamado TNF-ReceptorAssociated Periodic Syndrome (TRAPS), cuyo patrón de herencia es autosómico dominante ${ }^{(3)}$.

Estudios posteriores dieron como resultado el descubrimiento del gen $C I A S$-1, actualmente conocido como $N L R P_{3}$, que codifica para la proteína criopirina, cuyas mutaciones han sido ampliamente asociadas con los denominados síndromes periódicos asociados con criopirinas; estos son el síndrome autoinflamatorio familiar inducido por el frío (Familial Cold Auto-Inflammatory Syndrome, FCAS), el síndrome de MuckleWells y la enfermedad multisistémica inflamatoria de inicio neonatal (Neonatal Onset Multisystem Inflammatory Disease, NOMID), también conocida como síndrome articular, cutáneo y neurológico crónico infantil (Chronic Infantile Neurological Cutaneous and Articular (CINCA) Syndrome) ${ }^{(4)}$.

Estos descubrimientos han permitido avanzar en el entendimiento de las bases inmunopatogénicas de este grupo de síndromes autoinflamatorios y cada vez más se siguen conociendo otras asociaciones que involucran el inflamasoma con enfermedades cardiovasculares, metabólicas o neurológicas, como la enfermedad de Alzheimer, entre otras ${ }^{(5)}$.
El mecanismo por el cual las distintas mutaciones causan tan variado espectro fenotípico en los síndromes periódicos asociados con criopirinas, es poco conocido. Se destaca el rol esencial de la hipersecreción de interleucina $1 \beta^{(6)}$.

Los tratamientos basados en el bloqueo de la actividad biológica de la IL-1 $\beta$, proporcionan resultados considerables en la remisión clínica y de marcadores inflamatorios, por lo cual impactan positivamente en la calidad de vida de estos pacientes ${ }^{(7)}$.

\section{CRIOPIRINOPATÍAS O SÍNDROMES PERIÓDICOS ASOCIADOS CON CRIOPIRINAS,}

\section{CAPS}

Durante la última década, la comprensión de las características clínicas y moleculares de las enfermedades autoinflamatorias hereditarias se ha expandido enormemente. Las enfermedades autoinflamatorias abarcan un amplio espectro de entidades que se caracterizan por episodios recurrentes de fiebre e inflamación que comprometen múltiples órganos y tejidos. Sin embargo, a diferencia de los trastornos autoinmunitarios, los episodios de inflamación no están asociados con títulos elevados de autoanticuerpos o alteraciones de las células $\mathrm{T}^{(8)}$.

Las criopirinopatías hacen parte de estas enfermedades autoinflamatorias que se originan en defectos genéticos, los cuales llevan a alteraciones de la regulación de la inmunidad innata. El término de síndrome autoinflamatorio fue propuesto por Kastner y O'Shea en 1999, quienes describieron un grupo de entidades de etiología no infecciosa, sin componente autoinmunitario o asociado con inmunodeficiencias, que cursan con pérdida de la regulación inflamatoria determinada genéticamente ${ }^{(9)}$. Los síndromes autoinflamatorios se han incluido en la clasificación de las inmunodeficiencias primarias en las revisiones periódicas del grupo de expertos formado por la International Union of Immunology Societies ${ }^{(10)}$.

Las criopirinopatías, también llamadas síndromes periódicos asociados con criopirinas, son enfermedades raras, con un patrón de herencia autosómica dominante. Su incidencia en Estados Unidos es de 1:1'ooo.ooo, con una prevalencia de 300 a 500 individuos. Comprenden tres entidades clínicas, aunque pueden considerarse como un continuum de expresiones fenotípicas de distinta gravedad. Las tres 
entidades, que pueden sobreponerse entre ellas, son el síndrome autoinflamatorio familiar inducido por frío (FCAS), el síndrome de Muckle-Wells y el trastorno inflamatorio multisistémico de inicio neonatal (NOMID/ CINCA), llamado también síndrome infantil crónico neurológico, cutáneo, articular ${ }^{(11)}$. El primero es el más leve y el tercero es la forma más grave de estas enfermedades (tabla 1). En general, las tres entidades se caracterizan por episodios febriles recurrentes que se inician desde la infancia, acompañados de un brote como urticaria, no pruriginoso, con artritis, artralgias o ambas ${ }^{(12)}$.

Las criopirinopatías son causadas por mutaciones en el gen NLRP3, también conocido como CIAS1 (ColdInduced Autoinflammatory Syndrome Gene-1), y este mecanismo patogénico es común en las tres enfermedades. Mientras que el patrón de herencia en el síndrome autoinflamatorio familiar inducido por frío y el sindrome de Muckle-Wells es generalmente familiar, la enfermedad puede deberse a mutaciones esporádicas en los pacientes con enfermedad neonatal multisistémica inflamatoria. La gravedad del fenotipo en pacientes no tratados con esta última enfermedad genera incapacidad para reproducirse, dado que los enfermos fallecen a edades tempranas, lo que hace que la mutación se manifieste de forma esporádica y no pueda ser heredada ${ }^{(13)}$.

El gen $N L R P 3$ se ubica en el cromosoma 1q44, se expresa en los neutrófilos, condrocitos y monocitos, codifica una proteína llamada criopirina, que es un componente de la estructura citoplásmica proteica denominada inflamasoma ${ }^{(14)}$. Este gen contiene nueve exones. En las criopirinopatías, las mutaciones se localizan predominantemente en el exón 3 que codifica para el dominio NACHT, el cual juega un papel crucial en la oligomerización de la criopirina ${ }^{(15,16)}$.

Algunas mutaciones puntuales del gen $N L R P_{3}$ promueven la formación aberrante del inflamasoma y una producción inapropiadamente elevada de IL-1 $\beta$ que, finalmente, van a determinar todo el espectro de síntomas inflamatorios, fiebre, elevación de reactantes de fase aguda producidos en el hígado y la neutrofilia que caracteriza a estos pacientes. Se cree que las distintas mutaciones tendrían un diferente impacto sobre la actividad del inflamosoma, lo que, modulado por la base genética individual, condicionaría la aparición de las distintas entidades clínicas ${ }^{(11,17)}$.

Tabla 1. Manifestaciones clínicas de los síndromes periódicos asociados con las criopirinas, de menor (FACS) a mayor gravedad (NOMID/CINCA)

\begin{tabular}{llll} 
CAPS & FCAS & SMW & NOMID/CINCA \\
Herencia & HAD & HAD & HAD, de novo \\
\hline Locus, gen, proteína & 1944, NLRP3, criopirina & $1944, \mathrm{NLRP}_{3}$, criopirina & La mayoría: 1944, NLRP3, criopirina \\
\hline Inicio & Infancia (primer año) & Infancia & Neonato \\
\hline Duración brotes & Horas-Días & Días-continuo & Continuo \\
\hline Manifestaciones cutáneas & Exantema urticariforme por frio & $\begin{array}{l}\text { Exantema urticariforme por frio } \\
\text { yotros desencadenantes }\end{array}$ & Exantema urticariforme \\
\hline Manifestaciones articulares & Poliartralgias & Poliartralgias y artritis & Artritis y deformidad articular \\
\hline Manifestaciones neurologica & Cefalea & Meningitis aséptica, sordera & Meningitis, retraso mental, sordera \\
\hline Manifestaciones oculares & Conjuntivitis & Conjuntivitis, epiescleritis & Conjuntivitis, uveítis \\
\hline Otras & Fiebre & Fiebre, dolor abdominal, & $\begin{array}{l}\text { Amiloidosis. } \\
\text { amiloidosis }\end{array}$
\end{tabular}

CAPS: síndromes periódicos asociados con criopirinas; FCAS: síndrome autoinflamatorio familiar inducido por frío; SMW: síndrome de Muckle-Wells; NOMID/-CINCA: enfermedad multisistémica inflamatoria de inicio neonatal - síndrome crónico, infantil, neurológico, cutáneo y articular 


\section{SÍNDROME AUTOINFLAMATORIO FAMILIAR INDUCIDO POR EL FRÍO, FCAS}

Se describió inicialmente en los años 40. Es una enfermedad hereditaria con un patrón autosómico dominante, que afecta al $50 \%$ de la descendencia con una penetrancia variable. La prevalencia de esta entidad es desconocida y hasta ahora no se ha observado predominio según sexo ${ }^{(18)}$.

Suele manifestarse por una erupción en piel acompañada de signos de inflamación sistémica (fiebre, astenia, conjuntivitis, artralgia y marcadores inflamatorios elevados), después de la exposición sistémica al frío. No debe confundirse con la urticaria de contacto por frío, la cual se caracteriza por angioedema, ausencia de inflamación sistémica y reacción rápida al tratamiento con antihistamínicos ${ }^{(19)}$. En el síndrome autoinflamatorio familiar inducido por frío, la prueba de estimulación con frío (prueba del cubo de hielo) es negativa y no suele formar una pápula de tipo urticaria ya que no está mediada por la liberación de histamina (20).

En cuanto a las características clínicas, en las series publicadas por Hoffman, et al. ${ }^{(21,22)}$, en 2001 y 2003, se evaluaron 81 pacientes con este síndrome pertenecientes a siete familias no emparentadas ${ }^{(18)}$. En su reporte, la enfermedad se presentó antes de los seis meses de vida en el $95 \%$ de los pacientes, con una media de 47 días (rango: 2 horas a 10 años), y la edad de inicio de los síntomas no pareció relacionarse con la gravedad de la enfermedad.

El tiempo de exposición al frío necesario para presentar los síntomas fue, en promedio, de 52 minutos (rango: 5 minutos a 3 horas). La temperatura necesaria para provocar los síntomas variaba mucho, aunque la media fue de $22{ }^{\circ} \mathrm{C}$. La inmersión en agua, el aire acondicionado y los cambios bruscos de temperatura, también pueden desencadenar los episodios. Entre la exposición al frío y la aparición de los primeros síntomas, puede existir un tiempo variable, con una media de 2,5 horas (rango: 10 minutos a 8 horas). Las manifestaciones clínicas son de corta duración, habitualmente inferior a 24 horas (rango: 30 minutos a 72 horas) ${ }^{(18,21,22)}$. En cuanto a los síntomas clínicos durante los episodios inflamatorios, Hoffman, et al., encontraron que el 100 $\%$ de los pacientes estudiados presentaban erupción cutánea de aspecto de urticaria en forma de placas eritematosas, en ocasiones confluentes y dolorosas, que causan sensación de quemazón más que prurito. $\mathrm{Su}$ localización en el $45 \%$ de los casos corresponde a las extremidades y, en el $30 \%$, a las extremidades y la cara. Las lesiones pueden aparecer en áreas no expuestas al frío. Los síntomas más comúnmente asociados con el episodio incluyen fiebre y escalofríos recurrentes (93\%), artralgias (96\%) y conjuntivitis (84\%). Otros síntomas son sudoración, somnolencia, cefalea, sed y náuseas ${ }^{(18,21,22)}$.

La manifestación articular suele consistir en poliartralgias, siendo este uno de los síntomas más incapacitantes. Las articulaciones mas comúnmente afectadas son las manos y los dedos (61\%), las rodillas (68\%) y los tobillos (54\%). Otras articulaciones involucradas incluyen los pies, las muñecas y los codos. No hay reportes de artritis.

En $84 \%$ de lo casos de síndrome autoinflamatorio familiar inducido por frío se presentan síntomas oculares y la inyección conjuntival es la queja más frecuente; también, se describen visión borrosa y dolor ocular. No se ha reportado edema periorbitario ${ }^{(18,21,22)}$.

\section{SÍNDROME DE MUCKLE-WELLS}

Fue descrito en 1962 por Muckle y Wells en una familia británica, como una entidad clínica de herencia autosómica dominante. Es la criopirinopatía de gravedad intermedia. Se caracteriza por inflamación, fiebre, erupción cutánea, artralgia, conjuntivitis, sordera neurosensorial y amiloidosis potencialmente mortal ${ }^{(23)}$. Los episodios de inflamación suelen durar de dos a cinco dias y pueden presentarse entre seis y ocho episodios anuales. Suele iniciarse con mayor frecuencia durante la infancia, aunque, en ocasiones, la enfermedad se diagnostica en la edad adulta con la presentación de las complicaciones típicas de la enfermedad ${ }^{(18)}$.

Entre las manifestaciones clínicas durante los episodios inflamatorios, se destaca la erupción cutánea, que se presenta en edades tempranas y suele ser urticariforme y confluente. Generalmente, se localiza en el tronco y las extremidades y, con menor frecuencia, compromete la cara. Su duración es variable y fluctúa entre 5 y 24 horas ${ }^{(18)}$. La mayoría de los pacientes puede presentar un exantema urticariforme en relación con la exposición al frío, pero también se han identificado otros factores desencadenantes, como la humedad y el estrés, a diferencia de lo que sucede en el el síndrome autoinflamatorio familiar inducido por frío, en el que el frío juega un papel fundamental. En ocasiones, no se detecta un factor desencadenante claro de las lesiones en piel ${ }^{(11)}$. Las lesiones cutáneas se asocian con fiebre, escalofríos, sudoración, dolor abdominal, vómitos y artralgias o artritis. 
El $75 \%$ de los pacientes con síndrome de Muckle-Wells presentan compromiso articular. Puede manifestarse como artralgias difusas o como artritis, habitualmente monoarticular $\mathrm{u}$ oligoarticular, principalmente con compromiso de rodillas, tobillos, hombros y pequeñas articulaciones de las extremidades. La conjuntivitis recurrente es la manifestación ocular más frecuente en este síndrome, aunque también se ha descrito uveítis anterior aguda $^{(11)}$.

Las manifestaciones neurológicas más frecuentes son la cefalea crónica y la irratibilidad, las cuales se deben al aumento de la presión intracraneal secundaria a episodios de meningitis aséptica crónica de intensidad leve ${ }^{(11)}$.

La manifestación que caracteriza a este síndrome es el compromiso auditivo, en forma de sordera neurosensorial, bilateral y progresiva. Suele aparecer hasta en $60 \%$ de los pacientes. La edad de presentación es variable; puede ser en los primeros años de vida, en la edad escolar o en la adolescencia, a diferencia de la amiloidosis, que es una complicación más tardía. Una hipótesis de la causa de la sordera relaciona el aumento de la IL-6 con un posible efecto en los osteoclastos, con la consiguiente destrucción del órgano de Corti y del nervio coclear. Sin embargo, al parecer, esta teoria no es correcta dado que también se ha encontrado elevación de la IL-6 en otras enfermedades autoinflamatorias que no causan sordera.

Hasta el $25 \%$ de los pacientes con síndrome de MuckleWells sufren amiloidosis. Habitualmente, aparece en la tercera década de la vida, como consecuencia de procesos inflamatorios repetitivos no controlados. Aunque puede afectar cualquier órgano o tejido, involucra especialmente al riñón; se manifiesta principalmente por proteinuria, que conlleva un síndrome nefrótico que evoluciona a insuficiencia renal terminal. La presencia de amiloidosis secundaria y la sordera, ensombrecen el pronóstico de estos pacientes ${ }^{(11,18)}$.

\section{ENFERMEDAD MULTISISTÉMICA INFLAMATORIA DE INICIO NEONATAL (NOMID)}

Fue descrita en 1981 por Prieur y Griscelli como una entidad independiente de la artritis reumatoide juvenil, y se denominó síndrome CINCA (crónico, infantil, neurológico, cutáneo y articular) en 1987. Posteriormente, Hassink y Goldsmith la denominaron enfermedad multisistémica inflamatoria de inicio neonatal (NOMID) (14). Este es el más grave de los síndromes periódicos asociados con criopirinas y, por tanto, el que tiene el peor pronóstico. La inflamación multiorgánica aparece desde el período neonatal. Afecta la piel en forma de “exantema urticariforme crónico", a las articulaciones y al sistema nervioso central. Debido al fenotipo tan grave, estos pacientes no alcanzan la edad para reproducirse y, por tanto, las mutaciones del gen $N L R P_{3}$ son esporádicas $^{(8)}$.

La gravedad de la enfermedad multisistémica inflamatoria de inicio neonatal, puede ser muy variable y, asimismo, el daño orgánico que se produce. Se han encontrado mutaciones del gen $\mathrm{NLRP}_{3}$ en 50 a $60 \%$ de los casos. Los pacientes que son negativos para la mutación del $N L R P_{3}$, podrían tener mutaciones en otras vías comunes en las que la criopirina participe y que resulten en la misma expresión fenotípica.

El compromiso de la piel se manifiesta por una erupción eritematosa urticariforme migratoria y no pruriginosa, que aparece antes de los seis meses de edad en la mayoría de los casos. En las dos terceras partes de los neonatos, hay lesiones dérmicas desde el nacimiento. La erupción persiste toda la vida de los pacientes.

Las manifestaciones clínicas, articulares y neurológicas, condicionan la calidad de vida de estos pacientes ${ }^{(24)}$. Están presentes en casi todos, e incluyen cefaleas, crisis convulsivas, episodios transitorios de hemiplejía, espasticidad, meningitis aséptica neutrofílica crónica, retraso del desarrollo y retraso mental. Se pueden afectar los órganos de los sentidos visual y auditivo. En el visual, se presentan uveítis anterior o posterior, $u$ alteraciones del nervio óptico que pueden conducir hasta la ceguera, y en el auditivo, puede encontrarse sordera neurosensorial ${ }^{(14)}$.

Varios de los pacientes con la enfermedad multisistémica inflamatoria de inicio neonatal presentan macrocefalia, prominencia del hueso frontal, cierre tardío de la fontanela anterior y deformidad de la nariz en silla de montar, lo cual les da la facies característica.

Las alteraciones músculo-esqueléticas consisten en acortamiento de manos y pies, que puede acompañarse de hipocratismo digital ('dedos en palillo de tambor'). El compromiso articular es un hallazgo constante en todos los pacientes con esta enfermedad y suele conducir a una artropatía grave y degenerativa. Se ha observado crecimiento excesivo y simétrico de la rótula y del fémur distal, y diversas anormalidades epimetafisiarias con hipertrofia de cartílagos sin engrosamiento sinovial. Suele encontrarse en ellos linfadenopatías y hepatoesplenomegalia. Los pacientes pueden fallecer a edades tempranas, y la mayoría de las muertes se deben a infecciones, vasculitis o amiloidosis ${ }^{(9,11,25)}$. 
DIAGNÓSTICO DE LOS SÍNDROMES PERIÓDICOS ASOCIADOS CON CRIOPIRINAS, CAPS

No es fácil diagnosticar las enfermedades autoinflamatorias, por lo que el retraso en su diagnóstico es habitualmente la norma y algunos de ellos, como en los síndromes periódicos asociados con criopirinas o criopirinopatías, tienen un regular pronóstico a largo plazo debido a la instauración de la amiloidosis secundaria. En el diagnóstico diferencial de estas enfermedades que cursan con fiebre recurrente, deben considerarse infecciones, neoplasias y enfermedades autoinmunitarias.

Durante los ataques, todas las enfermedades autoinflamatorias cursan con elevación de reactantes de fase aguda; también, pueden cursar con trombocitosis, eosinofilia y anemia por enfermedad crónica. En el abordaje de los pacientes con sospecha de enfermedades autoinflamatorias hereditarias que cursan con fiebre recurrente, se recomienda excluir inicialmente otras enfermedades, e investigar la historia familiar y las características clínicas. Si lo anterior no permite establecer el diagnóstico, se analizan las mutaciones genéticas específicas para la entidad en sospecha ${ }^{(10,26)}$. En el caso del síndrome autoinflamatorio familiar inducido por frío, Hoffman, et al., propusieron unos criterios diagnósticos que pueden orientar al médico tratante (tabla 2).

En general, el diagnóstico de las criopirinopatías se basa en la historia clínica detallada, los antecedentes familiares y la biopsia de piel. En la histopatología de piel, es común encontrar un infiltrado neutrofílico intersticial en la dermis reticular, con ausencia de mastocitos. El infiltrado tiende a ser perivascular y puede ser periecrino. La inmunofluorescencia es negativa ${ }^{(11)}$. El diagnóstico definitivo de los síndromes periódicos asociados con criopirinas, requiere del estudio genético que muestra mutaciones en el gen $N L R P_{3}$, codificador de la criopirina. Sin embargo, no hay que olvidar que, aunque la identificación genética positiva confirma el diagnóstico, su ausencia no invalida el diagnóstico clínico. Esto es especialmente cierto en la enfermedad multisistémica inflamatoria de inicio neonatal, pues solo el $50 \%$ de los pacientes que la presentan clínicamente son positivos para la mutación ${ }^{(27)}$. El patrón hereditario autosómico dominante se manifiesta en alrededor del $75 \%$ de los pacientes con síndrome de Muckle-Wells y síndrome autoinflamatorio familiar inducido por frío, mientras que, en el caso de la enfermedad neonatal multisistémica inflamatoria, suele ser esporádico; las mutaciones de novo en el gen $N L R P_{3}$ se pueden identificar en la mitad de los pacientes con esta enfermedad ${ }^{(28)}$.

En 2011, Tanaka, et al., publicaron los resultados de un estudio colaborativo internacional multicéntrico, cuyo objetivo era determinar la contribución de los 'mosaicismos' somáticos en el gen $N L R P_{3}$ en la etiología de la enfermedad neonatal multisistémica inflamatoria ${ }^{(29)}$. En este estudio se tuvieron en cuenta muestras de 26 pacientes con la enfermedad que eran negativos para la mutación del gen $N L R P 3$ y muestras de 19 parientes sanos. Se encontraron 'mosaicismos' somáticos del gen $N_{L R P}$ en 18 de los 26 pacientes afectados, lo que corresponde al 69,2\%. No se detectó ningún 'mosaicismo' en los 19 parientes sanos ( $\mathrm{p}<0,0001)$. Esto indica que el mosaicismo somático en $N L R P_{3}$ es una importante causa de esta enfermedad.

Si fuere posible diagnosticar los 'mosaicismos' somáticos del gen $N L R P_{3}$ en un tiempo razonable, con poca mano de obra y a bajo costo, la tasa de éxito del diagnóstico genético de la enfermedad neonatal multisistémica inflamatoria, aumentaría de 60 a $80 \%$ o más, lo que permitiría en gran medida mejorar la salud y el pronóstico de estos pacientes, evitando lesiones irreversibles y las complicaciones neurológicas de esta enfermedad ${ }^{(30)}$.

\section{BASES INMUNOPATOGÉNICAS DE LOS SÍNDROMES PERIÓDICOS ASOCIADOS CON CRIOPIRINAS, CAPS}

\section{Inflamasoma NLRP3}

En el año 2001, se dio un gran paso en el conocimiento de las bases genéticas de los síndromes periódicos asociados con criopirinas, después de que el inmunogenetista Hal Hoffman lograra identificar al gen CIAS-1 (Cold-Induced Autoinflammatory Syndrome-1) localizado en el cromosoma 1q44, como el causante del síndrome autoinflamatorio familiar inducido por frío y el síndrome de Muckle-Wells ${ }^{(31)}$. Posteriormente, en 2002, se logró asociar la aparición de mutaciones del mismo gen, como responsables de la enfermedad neonatal multisistémica inflamatoria ${ }^{\left.{ }^{32}\right)}$. Finalmente, el proyecto Genoma Humano (HUGO, Human Genome Organization) aprobó el nombre de $\mathrm{NLRP}_{3}$ (NOD-Like 
Receptor Family, Pyrin-Domain Containing 3) para el gen inicialmente nombrado CIAS-1 por Hoffman.

En este mismo año, se propuso el concepto de inflamasoma al identificar la criopirina (también denominada proteína Nalp3) y su relación con las caspasas proinflamatorias en el ensamblaje de una plataforma multiproteica para el procesamiento de la interleucina $1 \beta$ y otras interleucinas proinflamatorias ${ }^{(33,34)}$.
En la proteína criopirina pueden reconocerse tres regiones fundamentales: una región central, que corresponde al dominio NACHT de oligomerización con actividad de ATP-asa; la región C- terminal, correspondiente a repeticiones ricas en leucina (LRR), que funciona como componente receptor de ligandos, y una porción N-terminal, que es el dominio pirina (PYD) de la proteína que le permite su interacción con la proteína

Tabla 2. Criterios diagnósticos que sugieren síndrome autoinflamatorio familiar inducido por frío

Episodios de fiebre y exantema recurrentes, de aparición natural o experimental provocados por el frío

Enfermedad hereditaria con patrón autosómico dominante

Edad de inicio antes de los seis meses de vida

Duración de los episodios menor de 24 horas

Presencia de conjuntivitis en los episodios

Ausencia de sordera, edema periorbitario, adenopatías y serositis

\section{BASES GENÉTICAS}

La región codificadora del gen $N L R P 3$ consta de 9 exones. Se destaca por su importancia el exón 3 que codifica el dominio de oligomerización NACHT, ya que allí se localizan cerca del $90 \%$ de las mutaciones identificadas en los síndromes periódicos asociados con criopirinas ${ }^{(4)}$. La mutación más frecuentemente encontrada ha sido la R26oW (cambios de arginina en la posición 260 por triptófano), según se reportó en el registro Eurofever, donde se incluyeron 136 pacientes con criopirinopatías de una base de datos en un período de tres años (entre noviembre de 2009 y junio de 2012) (35). A la fecha, se han identificado 172 mutaciones, de las cuales 167 son por sustitución de un aminoácido (http://fmf.igh.cnrs.fr/ISSAID/infevers/).

\section{FORMACIÓN DEL INFLAMASOMA}

La proteína criopirina, perteneciente a la familia de receptores de tipo Nod del sistema inmunitario innato, compuesta por 1.034 aminoácidos y con un peso molecular de $117.9 \mathrm{kD}$, es expresada de forma preferencial por monocitos, neutrófilos, células dendríticas y condrocitos ${ }^{(31,36)}$. adaptadora ASC (Apoptosis-associated Speck-like protein containing a $C A R D$ ) mediante interacciones homotípicas ${ }^{(34)}$.

El último componente del inflamasoma $\mathrm{NLRP}_{3}$ es la caspasa-1, que pertenece al grupo de las llamadas caspasas inflamatorias para diferenciarlas de las caspasas apoptóticas. Los genes que codifican para estas caspasas se encuentran en el cromosoma 11q22, especí-

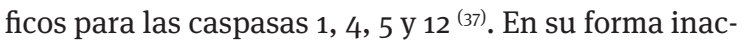
tiva, esta caspasa se encuentra como procaspasa-1, la cual, luego de interactuar con su dominio CARD (Caspase Recruitment Domain) localizado en su extremo Nterminal ${ }^{\left({ }^{8}\right)}$, y por interacción homotípica con el mismo dominio de la proteína adaptadora ASC, es convertida en caspasa-1 por un proceso de autocatálisis ${ }^{(39)}$. Después de activada, esta caspasa-1 es capaz de escindir a la pro-interleucina $1 \beta$, dejándola en su forma activa, es decir, la citocina proinflamatoria interleucina $1 \beta$ (IL-1 $\beta$ ) que, finalmente, es la responsable de las manifestaciones clínicas. No obstante, aún se encuentra en estudio cuál es el papel en la fisiopatología de estos síndromes de otras dos interleucinas, la IL-18 y la IL33. que también son escindidas por la misma caspasa ${ }^{(40)}$. En la figura 1 se presenta un esquema del inflamasoma NLRP3. 


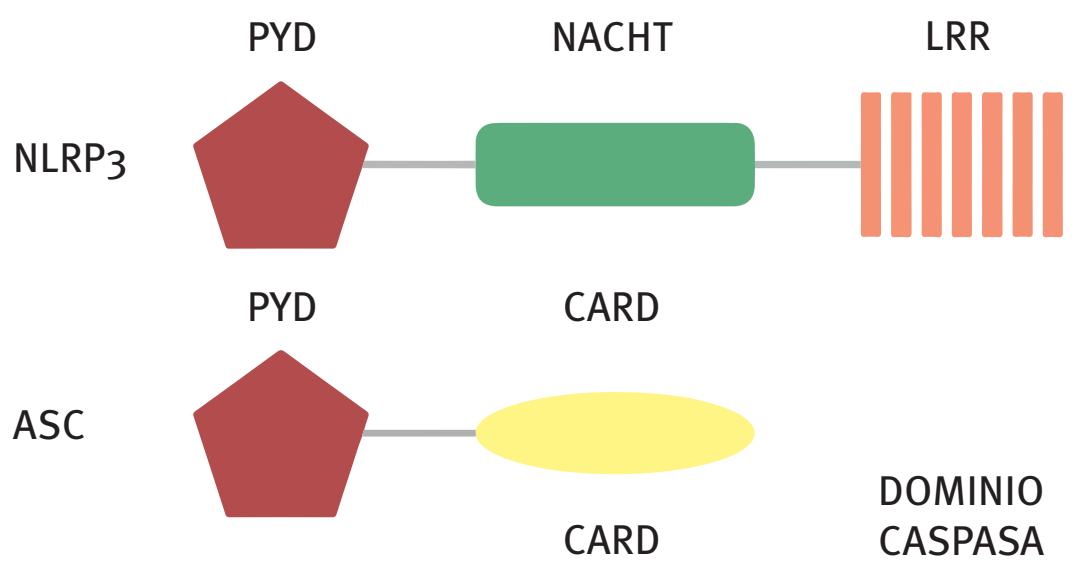

\section{CASPASA-1}

Figura 1. Esquema de los diferentes componentes del inflamasoma NLRP3, con sus respectivos dominios. En la criopirina pueden reconocerse tres regiones fundamentales: la central, que corresponde al dominio NACHT de 'oligomerización' con actividad de la ATP-asa; la C-terminal, correspondiente a repeticiones ricas en leucina (LRR), que funciona como componente receptor de ligandos; y una porción $\mathrm{N}$-terminal, que es el dominio pirina (PYD) de la proteína que le permite su interacción con la proteína adaptadora ASC (Apoptosis-associated Speck-like protein containing a CARD) mediante interacciones homotípicas. Por interacción con el mismo dominio de la proteína adaptadora ASC, la procaspasa-1 es convertida a caspasa-1 mediante autocatálisis. Las figuras idénticas representan los lugares donde interactúan estos componentes.

\section{MODELOS DE ACTIVACIÓN}

Se han descrito dos modelos para la activación del inflamasoma NLRP3. El primero, denominado la vía canónica de activación, involucra a receptores de tipo toll (TLR, Toll-Like Receptors), especialmente el de tipo 4, receptores de la familia de la IL-1 y receptores para el TNF (factor de necrosis tumoral), en cuyo caso, diferentes patrones moleculares asociados con patógenos (PAMP) microbianos, patrones moleculares asociados con daño (DAMP) endógenos dan lugar a cambios en el microambiente intracelular que, finalmente, llevan a la activación del inflamasoma ${ }^{(41)}$. Las señales exógenas (PAMP) pueden corresponder a productos microbianos como lipopolisacáricos, ácidos nucleicos y el muramil dipéptico, y toxinas como la nigericina o la maitotoxina que son formadoras de poros. En cuanto a las señales endógenas (DAMP), se encuentran cristales (urato monosódico, pirofosfato cálcico, cristales de colesterol), ácidos grasos libres, LDL oxidadas, ATP, depósitos de amiloide y, finalmente, productos exógenos actúan como estresores ambientales, entre estos, sílice, asbesto, aluminio, radiación ultravioleta e irritantes cutáneos ${ }^{(42)}$.

La segunda vía de activación, denominada no canónica, involucra a la caspasa-11 en la activación del inflamasoma en modelos de ratón, en los cuales esta caspasa parece tener la capacidad de activar a la caspasa-1 y, por esta vía, generar IL-1 $\beta$, lo que lleva a una forma de muerte celular mediada por inflamación denominada piroptosis, por mecanismos aún no del todo dilucidados ${ }^{(43)}$.

Con base en la secuencia de aminoácidos, la homóloga en humanos de esta caspasa sería la caspasa 4 o la 5. Esta vía se desencadena principalmente por la infección de microorganismos Gram negativos, como Escherichia coli, Vibrio cholerae o Citrobacter rodentium que, al parecer, escapan del fagolisosoma y, de este modo, activan la caspasa-11 ${ }^{(44)}$.

Después de la estimulación de los receptores de membrana ya mencionados, se genera una serie de señales intracelulares que conducen a la liberación del factor nuclear kappa B (NF-kB) y su traspaso al núcleo, donde participa en la transcripción del gen $N L R P_{3}$ para la 
formación de la criopirina y en la transcripción de la pro-IL-1 $\beta$. Este proceso inicial de activación es llamado de iniciación (priming) y comprende toda la cascada de eventos, desde la estimulación de los receptores de membrana y sensores intracelulares como el NOD2, hasta la producción de las proteínas antes mencionadas ${ }^{(45)}$.

En su estado inactivo, la criopirina (proteína Nalp3) se encuentra plegada gracias a la presencia de unas proteínas chaperonas (HSP9o, SGT1) y a su 'ubicuitinación' después de salir del retículo endoplásmico, lo que deja a su dominio LRR plegado sobre el dominio NACHT, impidiendo su oligomerización espontánea ${ }^{(45)}$. El segundo paso, llamado activación, involucra una serie de cambios en el ambiente intracelular que son desencadenados por los patrones moleculares (PAMP o DAMP) y llevan a la producción de especies reactivas de oxígeno (ROS) generadas por estrés mitocondrial, y también, a disminución del potasio intracelular, y aumento de la concentración de calcio citoplásmico y del ATP. Posteriormente, una desubicuitinasa llamada BRCC3 permite la apertura del dominio LRR de la criopirina y la exposición de su dominio central NACHT que, mediante su actividad ATP-asa, conducirá a su 'oligomerización' y al reclutamiento de la proteína adaptadora ASC y su interacción con la procaspasa-1, formando el inflamasoma propiamente dicho (45).

Mucho es lo que se ha dicho de los mecanismos de activación del inflamasoma NLRP3. Sin embargo, se ha recalcado que es poco probable que, por su variedad estructural, estos factores activadores interactúen directamente con la criopirina y, más bien, actúan induciendo diversos cambios en el ambiente citoplásmico que conducen, finalmente, a la formación del mencionado inflamasoma y a la producción de la interleucina $1 \beta^{(46)}$. En la figura 2 se describen las generalidades de la activación del inflamasoma.

\section{MECANISMOS DE INHIBICIÓN}

Se han descrito varios mecanismos de inhibición naturales del inflamasoma, aunque de la misma forma como sucede con la activación, sus bases moleculares no están completamente dilucidadas. Se ha encontrado que, mediante interacciones de CD40 con el CD4OL, que los linfocitos $\mathrm{T}$ pueden inhibir la activación del inflamasoma $\mathrm{NLRP}_{3}{ }^{(47)}$, al igual que las señales generadas por la estimulación de receptores para el interferón alfa (IFNAR) y el gamma (IFNGR), ambos por activación de la óxido nítrico sintetasa inducible (iNOS), lo que conlleva la nitrosilación de la criopirina ${ }^{(48)}$. El estímulo del receptor IFNAR también inhibe la transcripción de la pro-IL-1 $\beta$ al aumentar la producción de la interleucina 10 (IL-10). Los niveles de AMP cíclico también llevan a la inactivación del inflamasoma (45). Por último, se ha podido demostrar que el microRNA miR-223 es un regulador crítico, ya que suprime la expresión de la criopirina, lo que se traduce en una reducción de la actividad del inflamasoma $\mathrm{NLRP}_{3}{ }^{(49)}$. X

\section{TEORÍA DE LA}

\section{INMUNOPATOLOGÍA DE LOS SÍNDROMES PERIÓDICOS ASOCIADOS CON CRIOPIRINAS, CAPS}

Si bien se ha avanzado mucho en el entendimiento de los mecanismos de formación y activación naturales del inflamasoma, poco se sabe de las bases inmunopatológicas de una criopirina alterada en su estructura $\mathrm{y}$, por lo tanto, en su función, que conlleva el amplio espectro de estos síndromes. Una de las principales hipótesis hace referencia a que las mutaciones del gen $N L R P_{3}$ resultan en la pérdida de la forma cerrada "en bisagra” de la criopirina, haciéndola más propensa a la 'oligomerización', con el subsiguiente ensamblaje del inflamasoma ${ }^{(50)}$.

Otra perspectiva interesante tiene que ver con el rol de la proteína adaptadora CARD 8 (Caspase Recruitment Domain-Containing Protein 8), también conocida como Cardinal, que contiene un dominio FIIND en su extremo N- terminal, el cual interactúa con el dominio NACHT de la criopirina; además, esta proteína adaptadora tiene un dominio CARD que puede interactuar con la caspasa-1, ejerciendo una regulación negativa sobre la misma ${ }^{(51,52)}$. Sin embargo, en el contexto de una criopirina mutada, la CARD 8 no puede interactuar con el dominio de 'oligomerización' y, por lo tanto, no puede ejercer su función ' como freno de la activación del inflamasoma ${ }^{(53)}$.

Una última propuesta un poco más general involucra el equilibrio de oxidoreducción (redox) entre los radicales libres de oxígeno y antioxidantes como factores claves en estos síndromes. Los cambios en el microambiente de oxidorreducción modulan el potencial de activación del inflamasoma NLRP3, los cuales, en condiciones fisiológicas, si no son de la suficiente magnitud no llegan a activarlo. Sin embargo, al haber una criopirina mutada, pequeños cambios en este equilibrio de oxidorreducción llevan a su activación y a liberación de grandes cantidades de IL-1 $\beta^{(54,55)}$. 


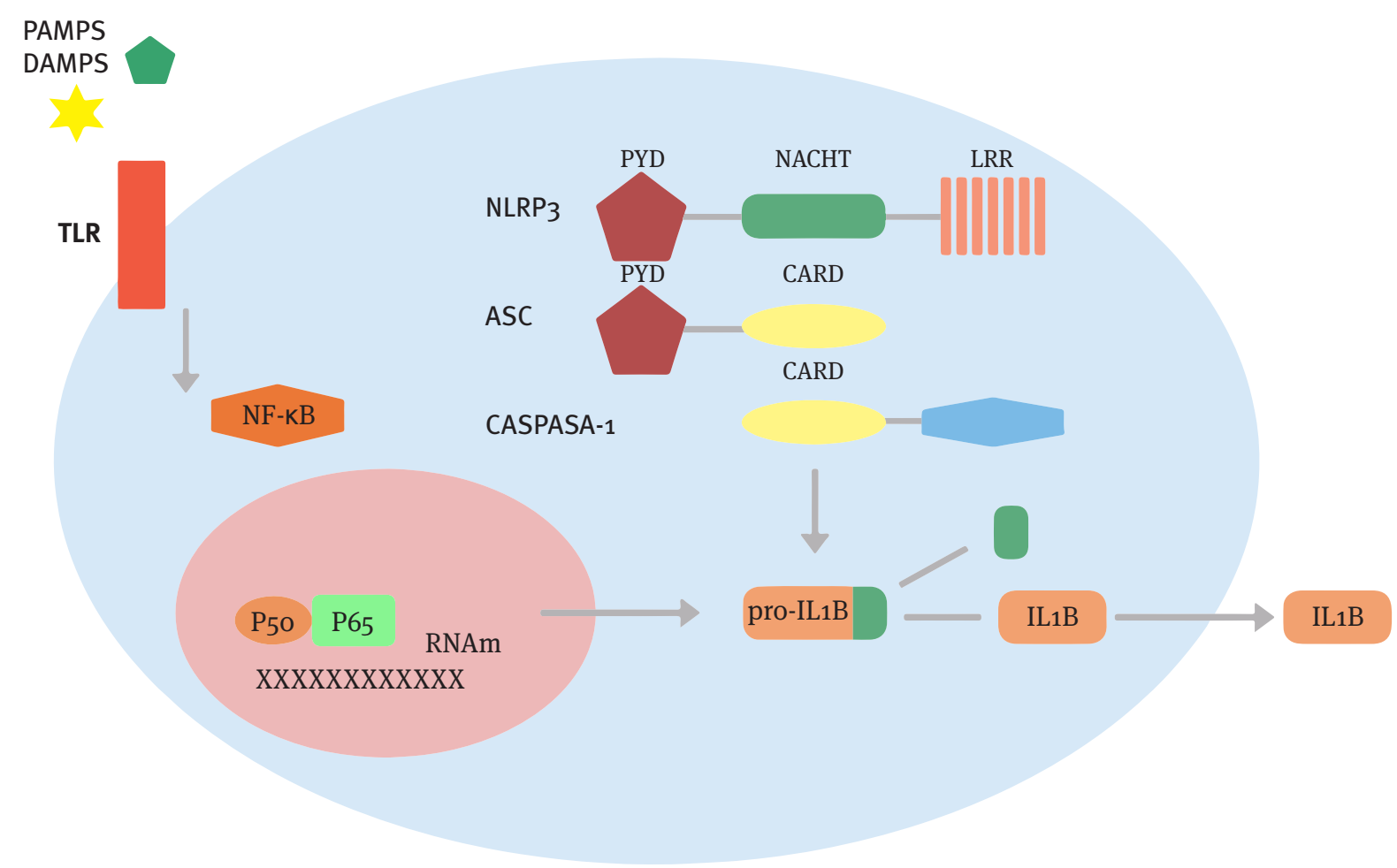

Figura 2. Generalidades del inflamosoma y su activación. Mediante interacción con los receptores toll-like (TLR), diferentes patrones moleculares asociados con patógenos (PAMP) microbianos y patrones moleculares asociados con daño (DAMP) endógenos, se producen cambios en el microambiente intracelular. Estos generan una serie de señales intracelulares que conducen a la liberación del factor nuclear kappa B (NF-kB) y su traspaso al núcleo, donde participa en la transcripción del gen $N L R P 3$ para formar la criopirina y en la transcripción de la pro-IL-1 $\beta$ que, finalmente, llevan a la activación del inflamasoma NLRP3 con activación de la caspasa-1. Esta escinde la proIL-1 $\beta$, liberando la interleucina biológicamente activa (IL-IL1 $\beta$ ), responsable de las manifestaciones clínicas de diferentes síndromes asociados con criopirinopatías.

CITOCINAS EN LA

INMUNOPATOGÉNESIS DE LOS SÍNDROMES PERIÓDICOS ASOCIADOS CON CRIOPIRINAS, CAPS

El objetivo del inflamasoma NLRP3 es generar, por medio de proteólisis, la forma activa de la caspasa-1 que procesa las citocinas IL-1 $\beta$, IL-18 e IL-33 de sus precursores a sus formas biológicamente activas. Las mutaciones del gen NLRP3 en los pacientes con estos síndromes generan un incremento en la actividad bio- lógica del inflamasoma, con hiperactividad de la caspasa-1, y dan como resultado la producción excesiva y no regulada de estas citocinas proinflamatorias ${ }^{(7)}$.

Las citocinas IL-1 $\beta$, IL-18 e IL-33 hacen parte de la familia IL-1, y están estrechamente ligadas a la reacción inflamatoria inmunitaria innata. La familia IL-1 se compone de 11 citocinas y, aunque la mayoría de ellas tienen acción proinflamatoria, algunos de sus miembros funcionan como inhibidores de la inflamación. La importancia de las diferentes citocinas de la familia IL-1 no radica en su estructura, sino en su capacidad de actuar como agonista o antagonista de su receptores específicos (tabla 3) ${ }^{(56)}$.

La familia de receptores IL-1 comprende 10 miembros, algunos de los cuales permanecen como receptores 
Tabla 3. Citocinas involucradas en la patogénesis de los síndromes autoinflamatorios familiares inducidos por frío (CAPS). La criopirina hiperfuncionante provoca la producción aumentada y no regulada de las citocinas IL-1B, IL-18 e IL-33, que hacen parte de los miembros de la familia del receptor de la IL-1 y son clave en las manifestaciones clínicas de estos síndromes.

\begin{tabular}{|c|c|c|c|}
\hline & $\mathrm{IL}-1 \beta$ & IL-18 & IL-33 \\
\hline Expresión de la citocina & $\begin{array}{l}\text { Macrófagos, células dendríticas } \\
\text { y endoteliales }\end{array}$ & $\begin{array}{l}\text { Células endoteliales, células } \\
\text { epiteliales, queratinocitos, } \\
\text { macrófagos, células dendríticas }\end{array}$ & $\begin{array}{l}\text { Células endoteliales, células } \\
\text { epiteliales, queratinocitos }\end{array}$ \\
\hline Receptor & $\begin{array}{l}\text { IL-1RI } \\
\text { Expresada en linfocitos T, } \\
\text { fibroblastos, condrocitos, células } \\
\text { endoteliales y células de } \\
\text { músculo liso }\end{array}$ & $\begin{array}{l}\text { IL-18R } \\
\text { Expresada en linfocitos T }\end{array}$ & $\begin{array}{l}\text { Complejo ST2 - IL-1RAcP } \\
\text { Expresado en linfocitos T, células } \\
\text { endoteliales, mastocitos y otras } \\
\text { células efectoras de la } \\
\text { inmunidad innata }\end{array}$ \\
\hline Efectos & $\begin{array}{l}\text { Síntesis de COX-2, fosfolipasa } \\
\text { A2, iNOS, PGE2 y factor activador } \\
\text { de plaquetas } \\
\text { Expresión de selectina E, ICAM1, } \\
\text { VCAM1, CXCL1 y CCL2 } \\
\text { Síntesis hepática de RFA } \\
\text { Factor activador de } \\
\text { diferenciación de osteoclastos } \\
\text { Pro IL-1 } \beta\end{array}$ & $\begin{array}{l}\text { Producción de IFN- } \gamma \\
\text { Expresión de GM-CSF, TNF, IL-1ß, } \\
\text { ON y quimiocinas }\end{array}$ & $\begin{array}{l}\text { Intranuclear: represor de la } \\
\text { transcripción } \\
\text { Activación de NF-kB o cinasas } \\
\text { MAP } \\
\text { Activación de mastocitos }\end{array}$ \\
\hline Acción biológica & $\begin{array}{l}\text { Fiebre, disminución del umbral } \\
\text { del dolor, vasodilatación, } \\
\text { inflamación crónica, } \\
\text { remodelación, artralgias y fatiga }\end{array}$ & $\begin{array}{l}\text { Inmunomoduladora } \\
\text { Diferenciación Th1 } \\
\text { Expansión de linfocitos T CD8+ }\end{array}$ & $\begin{array}{l}\text { Reguladora de la proliferación } \\
\text { endotelial } \\
\text { Potente activadora de Th2 e } \\
\text { inflamación alérgica }\end{array}$ \\
\hline
\end{tabular}

huérfanos. Estos receptores contienen un dominio citoplásmico de tipo TIR (Toll/IL-1 Receptor) con gran homología con los dominios citoplásmicos de los receptores de tipo toll (TLR), que traducen señales fundamentales en reacciones inflamatorias, como el aumento de la síntesis de moléculas de adhesión, quimiocinas, factores de crecimiento y diferenciación de células efectoras de la reacción inmunitaria, esenciales en la reacción inmunitaria innata ante la infección y el daño ${ }^{(57)}$. En el espacio extracelular, la mayoría de estos receptores presentan tres dominios de tipo inmunoglobulina, que los diferencian de los TLR que contienen un dominio de repeticiones ricas en leucina. Otra característica destacada es que, para la transducción de señales, estos receptores requieren una cadena de unión a su ligando más una segunda cadena que funciona como correceptor ${ }^{(58)}$.

\section{INTERLEUCINA $1 \beta$}

La IL-1 $\beta$ ha sido la citocina más estudiada y de mayor importancia en las enfermedades asociadas con mutación del gen $N L R P_{3}$. En cultivos de personas sanas y de pacientes con síndrome de Muckle-Wells y mutación del NLRP3 R26oW, Agostini, et al., aislaron monocitos y los estimularon con lipopolisacárido para medir los niveles de IL-1 $\beta$. Encontraron niveles mínimos o indetectables de la citocina en los controles sanos, que aumentaban más de seis veces su concentración después de la estimulación con lipopolisacárido en una proporción equivalente a la encontrada en pacientes con el síndrome y sin estimulación ${ }^{(59)}$.

Después de su síntesis y liberación en forma activa, esta citocina se une con baja afinidad al receptor de tipo 1 para la IL-1, llamado IL-1RI (Interleukin 1 Receptor, type 
I), que es el responsable de su actividad biológica. La unión con el el IL-1RI por sí sola no causa transducción de señales, pero facilita un cambio en la conformación del receptor, el cual le permite interactuar con su correceptor, la proteína accesoria del receptor de la IL-1, denominada IL-1RAcP (Interleukin 1 Receptor Accesory Protein), para formar un heterodímero.

Con la dimerización, se produce un acercamiento de los dominios TIR citoplásmicos de la IL-1RI y la IL-1RAcP, que lleva al reclutamiento de la proteína adaptadora MyD88. La unión de la MyD88 con los dominios TIR, desencadena la fosforilación de las cinasas asociadas con los receptores de la IL-1 (IL-1 Receptor-Associated Kinase), IRAK4, IRAK 2 e IRAK 1, con el consecuente reclutamiento del factor asociado con el receptor del TNF, TRAF6 (TNF Receptor Associated Factor-6). La IRAK1 fosforilada y el TRAF6 migran a la membrana y se asocian con la cinasa activada del TFG- $\beta$, llamada TAK1 (Transforming growth factor beta-Activated Kinase 1) que, a su vez, interactúa con las proteínas adaptadoras TAB1 y TAB2.

El complejo formado por TAK1, TAB1, TAB2 y TRAF6, migra al citosol donde la TAK1 es fosforilada después de la ubiquitinación del TRAF6. La proteína TAK1 fosforilada activa la cinasa IKK $\beta$, que fosforila la proteína inhibidora del factor nuclear kappa B, llamada IкB (Inhibitor of $\kappa B$ ), la cual es degradada posteriormente, dejando libre al factor de transcripción NF-кB (Nuclear Factor $\kappa B$ ) para que estimule, en el núcleo, la expresión de diferentes genes que codifican moléculas esenciales en la inflamación ${ }^{(60)}$.

La interacción de la IL-1 $\beta$ con su receptor IL-1RI, es regulada por el receptor de tipo II de IL-1, que funciona como señuelo, tiene más afinidad por la IL-1, y compite por la dimerización de la IL-1RI y la IL-1RAcP, pero no contiene un dominio TIR citoplásmico, por lo que no se desencadena la cascada de señalización.

Además, existe una proteína antagonista del receptor de IL-1 llamada IL-1Ra, que hace parte de la familia de la IL-1, expresada en monocitos y reconocida en la década de los 90 como la primera proteína antagonista natural contra un receptor; esta se une al IL-1RI con gran afinidad y evita la dimerización con la IL-1RAcP, evitando así la interacción de la IL-1 $\beta$ con su receptor y la transducción de señal. Sin embargo, este modo de regulación funciona con cantidades bajas o normales de IL-1 $\beta$, por lo que no es eficiente en el contexto de los síndromes periódicos asociados con criopirinas ${ }^{(61)}$. La acción de la IL-1ß, mediada por el factor de transcripción NF-kB, puede explicar las diferentes manifestaciones clínicas de dichos síndromes: la capacidad de la IL-1 $\beta$ para inducir la expresión génica y la síntesis de la ciclooxigenasa de tipo 2 (COX-2), la fosfolipasa A2 y la sintetasa inducible del óxido nítrico (iNOS) (inducible Nitric Oxide Synthase), genera producción de prostaglandina E2 (PGE2), factor activador de plaquetas y óxido nítrico (NO).

Como efecto sobre el sistema nervioso central, se genera fiebre, disminución del umbral del dolor y vasodilatación. Con la inducción de la expresión de moléculas de adhesión, como selectina E, ICAM1, VCAM1 y quimiocinas CXCL1 y CCL2, facilita la infiltración de células inflamatorias desde la circulación en diferentes tejidos y células efectoras del sistema inmunitario, lo cual conlleva remodelación e inflamación crónica. En el hígado, se induce la producción de reactantes de fase aguda por efecto directo de la IL-1 $\beta$ o mediante la inducción de la producción de la IL-6 en las células endoteliales, como PCR, proteínas del complemento y factores de coagulación, con aumento del amiloide sérico que, en grandes cantidades circulantes, se acumula en los tejidos y genera amiloidosis secundaria. En el sistema osteomuscular, se induce la producción del ligando del receptor activador para el FN-kB, RANKL (Receptor Activator for Nuclear factor $K B$ Ligand), con aumento de diferenciación de osteoclastos y aumento de la resorción ósea, además de daño del cartílago por aumento de la síntesis de elastasas y colagenasas, que induce la producción y activación de linfocitos, neutrófilos y plaquetas. Mediante una vía de retroalimentación positiva, la IL-1 $\beta$ se une a su receptor en monocitos y macrófagos para aumentar la producción de pro-IL-1B mediante el factor de transcripción NF-kB $(60,62)$.

\section{INTERLEUCINA 18}

La interleucina 18 es considerada como una citocina inmunomoduladora, al promover la diferenciación de células Th1, aumentar expansión de linfocitos T CD18+ e inducir producción de IFN-y en asociación con la IL12, que funciona como regulador de la expresión de su receptor. Puede aumentar la liberación de IL-1 $\beta$ y TNF en los monocitos. Se expresa de manera constitutiva en células endoteliales, células epiteliales y queratinocitos, y su principal fuente de liberación son los macrófagos y las células dendríticas.

La IL-18 se une con escasa afinidad a la cadena alfa de su receptor, IL-18Ra, que, al formar un complejo con su correceptor IL-18R $\beta$, forma un heterodímero; los dominios TIR citoplásmicos se aproximan y desencadenan la cascada de reclutamiento secuencial de MyD88, las cuatro IRAK y el TRAF-6, que culmina en la degrada- 
ción de IкB y la liberación del NF-kB, casi de manera idéntica como sucede en la vía de señalización de IL$1 \beta$.

También, a manera de regulación negativa, presenta un receptor de tipo señuelo que carece de dominio TIR y no transduce señales, llamado IL-18RaII. Además, existe una proteína soluble IL-18BP, que contiene los tres dominios IG de la cadena beta, que sirve también como regulador negativo de la acción de la IL-18, uniéndose a esta y evitando su interacción con el receptor, junto con la IL- $1 \mathrm{~F} 7$ que se comporta como inhibidora de esa citocina, ya que tiene la capacidad de unirse a la IL-18BP y formar un complejo que interactúa con el correceptor e impide que se forme el heterodímero con IL-18Ra, necesario para transducción de señal. Como citocina proinflamatoria, por la vía del NF-кB, la IL-18 aumenta las moléculas de adhesión, la síntesis de óxido nítrico y la producción de quimiocinas. La in ducción de fiebre no es una propiedad significativa de esta citocina, ya que no induce producción de ciclooxigenasa 2, por lo que no aumenta los niveles de prostaglandina E2 ${ }^{(63,64)}$.

Aunque no se ha logrado en seres humanos, en modelos animales se ha estudiado el papel de la IL-18 en inflamosomopatías. Brydges, et al., caracterizaron líneas de ratones con mutación del $N L R P_{3}$, que desarrollaban un fenotipo similar al de las criopirinopatías en humanos, pero con mayor gravedad en su espectro, con muerte perinatal en fenotipos similares a la la enfermedad neonatal multisistémica inflamatoria y muerte neonatal en fenotipos similares al síndrome de Muckle-Wells.

$\mathrm{Al}$ anular la vía de señalización de la IL-1 por medios genéticos o farmacológicos, estos individuos presentaron un modesto aumento en la expectativa de vida. Cuando criaron individuos con la mutación del gen de ratón $N_{L R P}$ knock-out para el receptor de la IL-18, observaron supresión de la enfermedad cutánea y visceral de los ratones jóvenes. Sin embargo, al avanzar en edad, estos individuos desarrollaron una importante inflamación sistémica, por lo que se puede deducir que la IL-18 cumple un papel importante en etapas tempranas de la enfermedad ${ }^{(65)}$.

\section{INTERLEUCINA 33}

La interleucina 33 se incluyó en la familia de la IL-1 en 2005, por la similitud de su estructura con la de otras citocinas de la familia y por su unión al receptor ST2 que hace parte de la familia de receptores de la IL-1. Se conoce por su función en el inicio y la perpetuación de la reacción Th2 y en la activación de los mastocitos, como parte de la reacción contra infestaciones por helmintos y en procesos alérgicos.

Está presente de manera constitutiva en diferentes tipos de células, entre ellas, células endoteliales, epiteliales y queratinocitos. Es una citocina de acción dual. Dentro de la célula, tras su síntesis en su forma activa, se ubica en el núcleo y se une a la cromatina, actuando como represor de la transcripción y controlando la proliferación celular ${ }^{(66)}$. Es liberada al espacio extracelular cuando se produce daño celular y necrosis. En la localización extracelular, la IL-33 se une a su receptor ST2 y forma un complejo con la proteína accesoria del receptor de la IL-1, IL-1RAc. La cascada de señalización desencadenada es muy similar a la de la IL-1 $\beta$, involucra el reclutamiento por dominios TIR de la proteína adaptadora MyD88, los receptores IRAK y el factor TRAF6 para la activación de factores de transcripción como el NF-KB ${ }^{(67)}$. No obstante, en el caso de las criopirinopatías, la función de esta citocina no se ha dilucidado.

\section{OPCIONES TERAPÉUTICAS EN LOS SIINDROMES PERIÓDICOS ASOCIADOS CON CRIOPIRINAS, CAPS}

Desde la primera descripción del síndrome autoinflamatorio familiar por frío en 1940 y hasta el 2004, los tratamientos utilizados para el control sintomático de las criopirinopatías, se centraban en evitar la exposición al frío, el manejo con antihistamínicos y antiinflamatorios no esteroideos, con pobres resultados. A mediados de los 70, se utilizaron tratamientos con sales de oro. Los corticoides fueron útiles para el control temporal de los síntomas, pero con sus efectos adversos conocidos a largo plazo. Además, fue común el uso de colchicina, dapsona, azatioprina, micofenolato, metotrexato, ciclosporina e infliximab, con reacciones terapéuticas poco satisfactorias. El descubrimiento de la mutación del gen $N L R P_{3}$, su relación con el inflamasoma y la importancia del aumento de la IL-1 $\beta$ en la fisiopatología de dichos síndromes, llevaron al desarrollo de nuevos tratamientos biológicos dirigidos a esta citocina como blanco terapéutico, con reacción rápida y sostenida en las manifestaciones clínicas y los marcadores de inflamación ${ }^{(68)}$.

En la figura 3 se esquematizan el mecanismo y el sitio de acción de los tres medicamentos actualmente dispo- 


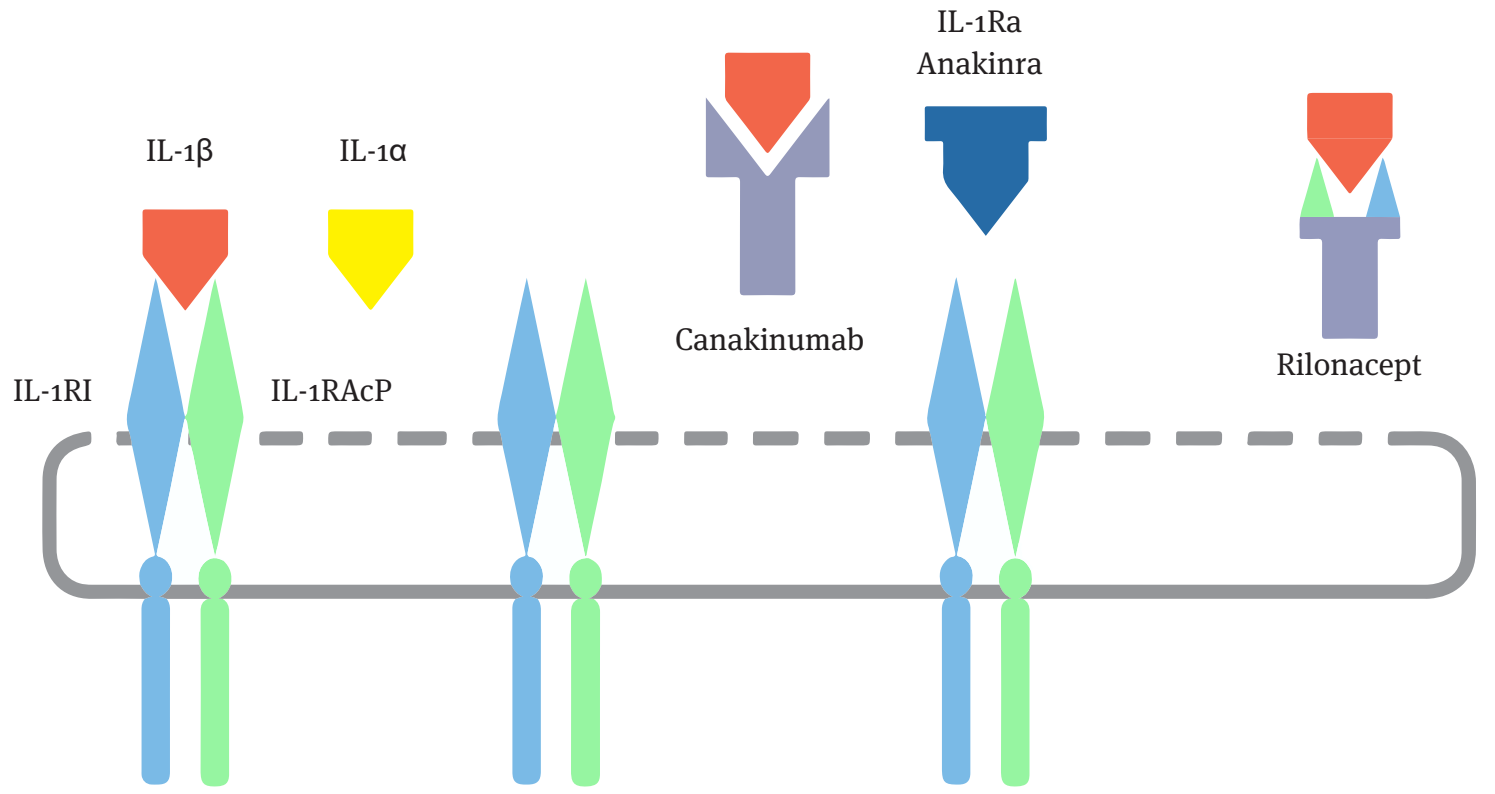

Figura 3. Opciones terapéuticas para bloquear la actividad biológica de la IL-1. Canakinumab es un anticuerpo monoclonal anti-IL-1 $\beta$ totalmente humanizado, que no presenta reacción cruzada con otros miembros de la familia de la interleucina 1, como IL-1 $\alpha$ o IL-1Ra. Anakinra es un homólogo recombinante del antagonista del receptor de la interleucina 1 (IL-1Ra) que inhibe de forma competitiva la unión de las moléculas IL-1 $\alpha$ e IL-1 $\beta$ con el receptor de la IL-1. Rilonacept es una proteína dimérica humana resultante de la fusión de la porción Fc de la IgG1 y de los dominios extracelulares de los dos componentes del receptor de la IL-1 (receptor de tipo 1 de la IL-1 y proteína accesoria al receptor de la IL-1), que actúa uniéndose a la IL-1, neutralizándola antes de que se pueda unir a los receptores de la superficie celular e inducir inflamación.

nibles para bloquear la actividad de la IL-1 $\beta$ en el tratamiento de las criopirinopatías: anakinra, una forma recombinante no glucosilada de la proteína antagonista del receptor de interleucina I (IL-1Ra); rilonacept, una proteína dimérica de fusión compuesta por el dominio extracelular del IL-1RI y la proteína accesoria IL-1RAc unidos a una fracción Fc de IgG; y canakinumab, un anticuerpo monoclonal recombinante humano antiIL-1 $\beta .{ }^{(69)}$.

\section{ANAKINRA}

El anakinra es el primer producto biológico diseñado para el bloqueo de la actividad de la IL-1. Fue introducido en 1993 para tratar pacientes con artritis reumatoide. Es una forma recombinante no glucosilada de la proteína antagonista del receptor de la interleucina 1 (IL-1Ra), elaborada a partir de cultivos de la bacteria E. coli modificada genéticamente, utilizando la tecnología ADN recombinante.

Compuesta por 153 aminoácidos, difiere de la proteína natural en la adición de un residuo metionina en su porción amino-terminal ${ }^{(70)}$. Su vida media es de cuatro a seis horas, por lo que su administración debe ser diaria; se administra por vía subcutánea a dosis de 1 a $3 \mathrm{mg} / \mathrm{kg}$ diarios hasta $100 \mathrm{mg} /$ dosis, aunque en pacientes con espectros más graves de la enfermedad se usan dosis hasta de $10 \mathrm{mg} / \mathrm{kg}$ al día ${ }^{(71)}$ (tabla 4). Fue aprobado por la Food and Drug Administration (FDA) en 2001, para el tratamiento de la artritis reumatoide en pacientes mayores de 18 años que no mejoran al tratarlos con uno o más fármacos antirreumáticos modificadores de la enfermedad y, en 2013, fue aprobado para tratar la enfermedad neonatal inflamatoria multisistémica ${ }^{(72)}$.

Los efectos secundarios del medicamento reportados han sido leves o moderados. Se ha presentado reacción en el sitio de la inyección hasta en $42 \%$ de los pacientes, pero desaparece en cuatro a seis semanas. Otros efectos adversos son aumento de las infecciones y aumento de peso ${ }^{(73)}$.

El primer reporte de la eficacia de anakinra se basó en una revisión de las características clínicas de una fa- 
Tabla 4. Mecanismo de acción, dosis y frecuencia de uso de los medicamentos anti-IL-1 disponibles

\begin{tabular}{|c|c|c|c|}
\hline & Anakinra & Canakinumab & Rilonacept \\
\hline Mecanismo de acción & $\begin{array}{l}\text { Forma recombinante no } \\
\text { glucosilada del antagonista del } \\
\text { receptor de la } \\
\text { IL-1 }\end{array}$ & $\begin{array}{l}\text { Anticuerpo monoclonal IgG1 } \\
\text { anti-IL-1 } \beta\end{array}$ & $\begin{array}{l}\text { Proteína dimérica de fusión con } \\
\text { dominio extracelular de la IL-1RI y } \\
\text { proteína accesoria IL-1RAcP } \\
\text { unidas a la fracción Fc de IgG1 } \\
\text { humana, que se une con gran } \\
\text { afinidad a la IL-1 } \beta\end{array}$ \\
\hline Dosis & $\begin{array}{l}1 \text { a } 3 \text { mg/kg/día, máximo } 100 \\
\mathrm{mg} / \text { dosis }\end{array}$ & $2-8 \mathrm{mg} / \mathrm{kg} /$ dosis & $\begin{array}{l}\text { Dosis de carga de } 4,4 \mathrm{mg} / \mathrm{kg} \text {, } \\
\text { máximo } 320 \mathrm{mg} \text { por dosis } \\
\text { Dosis de mantenimiento de } 2,2 \\
\mathrm{mg} / \mathrm{kg} \text {, máximo } 160 \mathrm{mg} \text { por dosis }\end{array}$ \\
\hline Frecuencia & Diaria & Cada 8 semanas & Semanal \\
\hline
\end{tabular}

milia de tres miembros con diagnóstico de síndrome de Muckle-Wells, mutación conocida en el gen $N L R P_{3}$ y enfermedad activa. Los tres individuos recibieron tratamiento con anakinra a una dosis extrapolada de la usada para la artritis reumatoide, de $100 \mathrm{mg}$ subcutáneos diarios, con un seguimiento basado en la medición diaria de síntomas, visitas clínicas semanales y medición de reactantes de fase aguda durante tres meses. Durante las primeras cuatro horas después de la administración de la primera dosis, se reportó resolución del brote cutáneo, la fiebre, la conjuntivitis y las artralgias. Los síntomas se mantuvieron en remisión durante el seguimiento, con significativa disminución de los marcadores de inflamación ${ }^{(74)}$.

Goldbach-Mansky, et al., llevaron a cabo un estudio prospectivo de 18 pacientes entre 4 y 32 años de edad, con diagnóstico de enfermedad neonatal inflamatoria multisistémica (SINCA/NOMID) y enfermedad activa, 12 de ellos con mutación del gen $N L R P_{3}$. Los pacientes se trataron con 1 a $2 \mathrm{mg} / \mathrm{kg}$ subcutáneos diarios de anakinra durante tres meses, tiempo al cabo del cual se suspendió el tratamiento; la administración del medicamento se reiniciaba si se agudizaban los síntomas, durante un seguimiento de seis meses. Se observó una rápida recaía en de los síntomas con la suspensión del tratamiento. A los tres meses de iniciado el tratamiento, el resultado más frecuente fue la disminución de los reactantes de fase aguda y del amiloide sérico, y la mejoría de síntomas, con remisión a los seis meses; además, hubo mejoría clínica del papiledema y la meningitis crónica y, de 17 pacientes con daño coclear, 13 presentaron mejoría y uno remisión de los síntomas ${ }^{(75)}$. Lepore, et al., evaluaron la calidad de vida de los pacientes con criopirinopatías manejados con anakinra, en un registro de diferentes centros de reumatología pediátrica en Italia. En su estudio se incluyeron 20 pacientes y se valoró su calidad de vida mediante un cuestionario de salud infantil (CHQ-PF 50), con un seguimiento de 37,5 meses. El tratamiento se asoció con una mejoría clínica importante y sostenida en las diferentes mediciones con respecto a la previa pobre calidad de vida de los pacientes, especialmente, en las relativas a la percepción de la salud global, el dolor o malestar corporal y otras manifestaciones físicas ${ }^{(76)}$.

\section{RILONACEPT}

El rilonacept es una proteína dimérica de fusión, compuesta por el dominio extracelular de IL-1RI y la proteína accesoria IL-1RAcP unidos a la fracción Fc de la IgG1 humana, que se une con gran afinidad a la IL-1 $\beta$, evitando su interacción con la IL-1RI y la transducción de señales. Su vida media es de 34 a 57 horas, por lo que se administra una vez por semana por vía subcutánea, en una dosis de carga de 4,4 mg/kg, máximo 320 $\mathrm{mg} /$ dosis, y una dosis de mantenimiento de 2,2 $\mathrm{mg} / \mathrm{kg}$, máximo16o mg por dosis ${ }^{(77)}$ (tabla 4). Fue aprobado por la FDA en 2008 para tratar el síndrome autoinflamatorio familiar por frío y el síndrome de Muckle-Wells, en adultos y niños mayores de 12 años. Los efectos secundarios reportados han sido leves o moderados y, los más comunes son reacción en el sitio de la inyección e infecciones respiratorias ${ }^{(78)}$.

La eficacia y la seguridad del rilonacept se evaluaron en un estudio abierto prospectivo de 5 pacientes entre 20 y 60 años de edad, con mutación del gen $N L R P 3$ y síndrome activo autoinflamatorio familiar por frío. 
El tratamiento se inició con una dosis de $300 \mathrm{mg}$ subcutáneos y, al presentarse una exacerbación sintomática, se continuaba con $100 \mathrm{mg}$ subcutáneos semanales como mantenimiento, hasta completar 24 meses de seguimiento. En los pacientes sin control de los síntomas, se escalonaba la dosis entre 160 y $320 \mathrm{mg}$ semanales. Se hizo el seguimiento durante 24 meses mediante valoración con una escala diaria de síntomas y la medición periódica de los reactantes de fase aguda. Se evidenció una rápida mejoría con estos dos parámetros de evaluación y se obtuvo su remisión durante el periodo de seguimiento. No se reportaron efectos adversos serios, pero sí aumento de peso en dos pacientes ${ }^{(79)}$.

En dos estudios consecutivos de fase III, Hoffman, et al., incluyeron 47 pacientes: 44 con síndrome autoinflamatorio familiar por frío y 3 con síndrome de Muckle-Wells, todos con mutación del gen $N_{L R} P_{3}$ y enfermedad activa. Mediante asignación aleatoria, unos pacientes recibieron placebo y, otros, una dosis de carga de 320 mg subcutáneos de rilonacept seguida por 160 mg subcutáneos semanales.

La eficacia del medicamento se evaluó mediante un formato diario de evaluación en salud (DHAF), donde los pacientes consignaban sus sintomas clave en las últimas 24 horas y su asociación con exposición a bajas temperaturas o limitación para desempeñar las actividades cotidianas. El puntaje en la escala DHAF disminuyó en el 84 \% del grupo tratado con rilonacept y en $13 \%$ del que recibió placebo. Los efectos secundarios más comunes fueron la reacción en el sitio de la inyección y el aumento de las infecciones respiratorias leves ${ }^{(80)}$.

Posteriormente, esta muestra de pacientes ingresó a un estudio abierto de extensión; los pacientes adultos recibieron $160 \mathrm{mg}$ subcutáneos semanales de rilonacept y, los pediátricos, 2,2 $\mathrm{mg} / \mathrm{kg}$ semanales. Se hizo un seguimiento de 72 semanas mediante un formato diario para evaluar la salud y con medición de los reactantes de fase aguda. Según estos dos parámetros, la mejoría clínica fue persistente y se obtuvo un perfil de seguridad favorable; además, hubo tolerabilidad en el grupo de pacientes pediátricos durante el período de extensión ${ }^{(81)}$.

\section{CANAKINUMAB}

El canakinumab es un anticuerpo monoclonal humano recombinante IgG1 anti-IL-1 $\beta$, que se une con gran afinidad a la IL-1 $\beta$, sin reacción cruzada con la IL-1a o la IL-1Ra, y neutraliza la actividad biológica de la citocina ${ }^{(82)}$. Su vida media es de 21 a 28 días, y se administra por vía subcutánea cada 8 semanas en dosis de $2 \mathrm{mg} / \mathrm{kg}$, máximo $150 \mathrm{mg}$ (tabla 4). Además, su administración se describe como menos dolorosa y presenta menos reacción en el sitio de inyección, en comparación con los otros dos medicamentos disponibles. Fue aprobado por la FDA en 2009 para el tratamiento de las criopirinopatías ${ }^{\left({ }^{8}\right)}$.

La eficacia y la seguridad del canakinumab se evaluaron en un estudio multicéntrico, controlado y de tres fases, en el que se incluyeron 35 pacientes con mutación del gen $N L R P_{3}$ conocida y síndrome de MuckleWells clínicamente activo. En la primera fase, abierta y de 8 semanas, se administró una dosis de $150 \mathrm{mg}$ subcutáneos del medicamento. En la segunda fase, se asignaron aleatoriamente los pacientes que mejoraron con la primera dosis, para recibir $150 \mathrm{mg}$ subcutáneos del medicamento o placebo, tres dosis cada ocho semanas. En la la tercera fase, con agudización de síntomas o después de completar la segunda fase, se administraron dos dosis más, cada una de $150 \mathrm{mg}$ subcutáneos. Todos los pacientes que recibieron canakinumab permanecieron libres de síntomas, mientras que 13 de los 16 que recibieron placebo presentaron una recaída hacia la semana 32 de seguimiento. Los efectos secundarios fueron el aumento de la incidencia de infecciones respiratorias superiores y un episodio de vértigo ${ }^{\left({ }^{84}\right)}$.

Koné-Paut, et al., llevaron a cabo un estudio doble ciego y de asignación aleatoria, sobre el impacto del tratamiento con canakinumab en la sintomatología y la calidad de vida de los pacientes con criopirinopatías, evaluados mediante escalas de calidad de vida para adultos y niños, como la HRQoL, la SF-36 y la CHQ-PF 28. Los puntajes en dichas escalas alcanzaron o superaron los de la población general de Estados Unidos en la semana 8 de tratamiento, y se mantuvieron estables durante el seguimiento. La mejoría en el dolor corporal y la función física fue particularmente significativa: aumentó en más de 25 puntos desde el inicio hasta la semana 8 de tratamiento ${ }^{(85)}$.

El Eurofever Registry es un registro internacional de enfermedades autoinflamatorias, en el cual participan 77 centros de 33 países, con datos obtenidos mediante la red PRINTO, y los centros de atención de adultos, interesados en el tratamiento de las enfermedades autoinflamatorias. Contiene una revisión retrospectiva y anónima de datos de los pacientes. Entre noviembre de 2009 y agosto de 2011, se incluyeron 496 pacientes con enfermedades autoinflamatorias, 94 de ellos con criopirinopatías. De estos pacientes, 86 recibieron al menos un anti-IL-1. De los 61 que recibieron anakinra, 39 (64\%) reportaron mejoría completa y, 21 (34\%), 
mejoría parcial. De 52 pacientes que recibieron canakinumab, 39 (75\%) reportaron mejoría completa y, 13 (25 $\%)$, mejoría parcial ${ }^{(86)}$.

En un estudio de fase III con 19 pacientes japoneses con criopirinopatías, que recibieron 2 a $8 \mathrm{mg} / \mathrm{kg}$ de canakinumab cada ocho semanas, se evidenció remisión completa en $79 \%$ de casos al día 15, en 94,7 \% a la semana 24, y en todos los casos, a la semana 48 . Todos los pacientes presentaron, al menos, un efecto secundario, especialmente infecciones respiratorias y reacciones en el sitio de inyección, y también, se presentó meningitis aséptica. En general, el medicamento mostró eficacia en el control del síndrome autoinflamatorio ${ }^{(87)}$.

\section{CONCLUSIONES}

Los criopirinopatías son enfermedades autoinflamatorias poco frecuentes, asociadas con mutaciones en el gen $N L R P_{3}$. Aunque su diagnóstico es clínico y molecular, la ausencia de mutaciones del NLRP3 no lo descarta y no se debe retrasar el inicio del tratamiento. En las criopirinopatías hay activación del inflamasoma con producción de IL-1ß. Las enzimas del huésped podrían ser cruciales para activar el inflamasoma y, al mismo tiempo, estas enzimas podrían representar una nueva diana terapéutica. Sigue siendo motivo de estudio si las moléculas sensoras del inflamasoma $\mathrm{NLRP}_{3}$ pueden reconocer directamente sus ligandos o si utilizan proteínas accesorias del huésped para este proceso.

Los tratamientos anti-IL-1 $\beta$ proveen remisión clínica rápida y sostenida en la mayoría de pacientes, son efectivos en los diferentes espectros de la enfermedad y bien tolerados, y causan pocos efectos secundarios reportados como leves o moderados. Se desconoce su efecto a largo plazo y continúa siendo materia de investigación, ya que los reportes sobre su eficacia y seguridad son relativamente recientes.

Quedan muchas preguntas importantes sin respuesta, incluyendo la forma en que las células huésped deciden cuál inflamasoma activar en condiciones particulares y cómo la señalización del inflamasoma se entrelaza con otras vías de la inmunidad innata y adaptativa. La relación entre las reacciones de oxidorreducción (redox) y la 'oligomerización' del inflamasoma, sigue sin dilucidarse. Además, existe la posibilidad de que se identifiquen otras mutaciones asociadas con la etiología de la enfermedad y nuevos blancos terapéuticos.

\section{REFERENCIAS}

1. Neven B, Prieur A-M, Quartier dit Maire P. Cryopyrinopathies: Update on pathogenesis and treatment. Nat Clin Pract Rheumatol. 2008;4:4819.

2. Aróstegui JI. Hereditary systemic autoinflammatory diseases. Reumatol Clin. 2011;7:45-50.

3. McDermott MF, Aksentijevich I, Galon J, McDermott EM, Ogunkolade BW, Centola M, et al. Germline mutations in the extracellular domains of the $55 \mathrm{kDa}$ TNF receptor, TNFR1, define a family of dominantly inherited autoinflammatory syndromes. Cell. 1999;97:133-44.

4. Sánchez G a M, de Jesús AA, Goldbach-Mansky R. Monogenic autoinflammatory diseases: Disorders of amplified danger sensing and cytokine dysregulation. Rheum Dis Clin North Am. 2013;39:701-34.

5. Takahashi M. NLRP3 inflammasome as a novel player in myocardial infarction. Int Heart J. 2014;55:101-5.

6. Chai J, Shi Y. Apoptosome and inflammasome: Conserved machineries for caspase activation. Natl Sci Rev. 2014;1:101-18.

7. Aróstegui JI. Etiopatogenia de los síndromes asociados a criopirina: genética, bases moleculares y el inflamasoma. Med Clin. 2011;136(Supl.1):22-8.

8. Ahmadi N, Brewer CC, Zalewski C, King KA, Butman JA, Plass N, et al. Cryopyrin-associated periodic syndromes: Otolaryngologic and audiologic manifestations. Otolaryngol Head Neck Surg. 2011;145:295-302.

9. Rojo E. Síndromes de fiebre recurrente y su relevancia en la medicina contemporánea. Acta Médica Grup Ángeles. 2009;7:150-7.

10. Jiménez S. De la fiebre periódica a los síndromes autoinflamatorios. Boletín de Pediatría. 2011;51:194-203.

11. Pérez B, Díaz M, Sexto L. Alergia, urticaria de contacto y síndromes urticariformes inducidos por frío. Galicia Clínica. 2012;73:151-9.

12. Vergara C. Síndromes autoinflamatorios. Rev Chil Reumatol. 2008;24:206-11.

13. Almeida de Jesús A, Goldbach-Mansky R. Monogenic autoinflammatory diseases: Concept and clinical manifestations. Clin Immunol. 2013;147:15574 .

14. Aboín-González S, Aldanondo-Fernández de la Mora I, García-Acebes ER, Carillo-Gijón R, HartoCastaño A, Jaén-Olasolo P. Exacerbation of skin lesions during fever in a patient with chronic infantile neurologic cutaneous articular syndrome. Actas Dermosifiliogr. 2008;99:481-4. 
15. Yu JR, Leslie KS. Cryopyrin-associated periodic syndrome: An update on diagnosis and treatment response. Curr Allergy Asthma Rep. 2011;11:12-20.

16. Gattorno M, Federici S, Pelagatti MA, Caorsi R, Brisca G, Malattia C, et al. Diagnosis and management of autoinflammatory diseases in childhood. J Clin Immunol. 2008;28(Suppl.1):S73-83.

17. Bolaños L, Mosquera-Reboredo JM, Cao M, Ferreiro T, Veleiro B, Valdés F, et al. Renal and thyroid amyloidosis secondary tocryopyrin-associated periodic syndrome (Muckle-Wells syndrome) (NLRP3 mutation). Nefrologia. 2013;33:266-71.

18. Penadés IC, Montesinos BL, Puche AM. Síndrome de Muckle-Wells y síndrome autoinflamatorio familiar inducido por frío. Med Clin. 2011;136(Supl.1):16-21.

19. Federici S, Gattorno M. A practical approach to the diagnosis of autoinflammatory diseases in childhood. Best Pract Res Clin Rheumatol. 2014;28:26376.

20. Furr JC, Panda M. Cold-induced urticaria with a familial transmission: a case report and review of the literature. J Med Case Rep. 2012;6:70.

21. Hoffman HM, Wanderer AA, Broide DH. Familial cold autoinflammatory syndrome: Phenotype and genotype of an autosomal dominant periodic fever. J Allergy Clin Immunol. 2001;108:615-20.

22. Johnstone R. A large kindred with familial cold autoinflammatory syndrome. Ann Alergy Asthma Immunol. 2003;90:233-7.

23. Kuemmerle-Deschner JB, Lohse P, Koetter I, Dannecker GE, Reess F, Ummenhofer K, et al. NLRP3 E311K mutation in a large family with MuckleWells syndrome--description of a heterogeneous phenotype and response to treatment. Arthritis Res Ther. 2011;13:R196.

24. Dávila-Seijo P, Hernández-Martín A, Torrelo A. Autoinflammatory syndromes for the dermatologist. Clin Dermatol. 2014;32:488-501.

25. Moreno S, Buestán A, Véliz C, Mora C, González S, Down D, et al. Síndromes autoinflamatorios para el dermatólogo. Dermatología Pediátrica Latinoamericana. 2007;5:9-18.

26. Hinojosa-Azaola A, Alcocer-Varela J. Enfermedades autoinflamatorias: una mirada a la inmunidad innata y su patología. Rev Investig Clin. 2012;64:477-86.

27. Calvo Ry C, Soler-Palacín P, Merino R, Saavedra J, Antón J, Aróstegui JI, et al. Consensus document on the differential diagnosis and therapeutic approach to recurrent fever by the Paediatric Infectology Society and the Paediatric Rheumatology Society. An Pediatr (Barc). 2011;74:194.e1-16.
28. Rowczenio DM, Trojer H, Russell T, Baginska A, Lane T, Stewart NM, et al. Clinical characteristics in subjects with $\mathrm{NLRP}_{3}$ V198M diagnosed at a single UK center and a review of the literature. Arthritis Res Ther. 2013;15:R30.

29. Tanaka N, Izawa K, Saito MK, Sakuma M, Oshima $\mathrm{K}$, Ohara $\mathrm{O}$, et al. High incidence of $N L R P_{3}$ somatic mosaicism in patients with chronic infantile neurologic, cutaneous, articular syndrome: Results of an International Multicenter Collaborative Study. Arthritis Rheum. 2011;63:3625-32.

30. Izawa K, Hijikata A, Tanaka N, Kawai T, Saito MK, Goldbach-Mansky R, et al. Detection of base substitution-type somatic mosaicism of the NLRP3 gene with $>99.9 \%$ statistical confidence by massively parallel sequencing. DNA Res. 2012;19:143-52.

31. Hoffman HM, Mueller JL, Broide DH, Wanderer AA, Kolodner RD. Mutation of a new gene encoding a putative pyrin-like protein causes familial cold autoinflammatory syndrome and MuckleWells syndrome. Nat Genet. 2001;29:301-5.

32. Feldmann J, Prieur A-M, Quartier P, Berquin P, Certain S, Cortis E, et al. Chronic infantile neurological cutaneous and articular syndrome is caused by mutations in CIAS1, a gene highly expressed in polymorphonuclear cells and chondrocytes. Am J Hum Genet. 2002;71:198-203.

33. Martinon F, Burns K, Tschopp J. The inflammasome: A molecular platform triggering activation of inflammatory caspases and processing of proIL-beta. Mol Cell. 2002;10:417-26.

34. Tschopp J, Martinon F, Burns K. NALPs: A novel protein family involved in inflammation. Nat Rev Mol Cell Biol. 2003;4:95-104.

35. Levy R, Gérard L, Kuemmerle-Deschner J, Lachmann HJ, Koné-Paut I, Cantarini L, et al. Phenotypic and genotypic characteristics of cryopyrinassociated periodic syndrome: A series of 136 patients from the Eurofever Registry. Ann Rheum Dis. 2014;18:1-7.

36. Kummer JA, Broekhuizen R, Everett H, Agostini L, Kuijk L, Martinon F, et al. Inflammasome components NALP 1 and 3 show distinct but separate expression profiles in human tissues suggesting a site-specific role in the inflammatory response. J Histochem Cytochem. 2007;55:443-52.

37. Martinon F, Boveresses C, Epalinges C-. Inflammatory caspases spasessn F, Bintracellular innate immune system to autoinflammatory diseases caspases not only play an essential role during apoptotic. Cell Press. 2004;117:561-74.

38. Proell M, Gerlic M, Mace PD, Reed JC, Riedl SJ. The CARD plays a critical role in ASC foci forma- 
tion and inflammasome signalling. Biochem J. 2013;449:613-21.

39. Shi Y. Caspase activation: Revisiting the induced proximity model. Cell. 2004;117:855-8.

40. Nasti T. Inflammasome activation of IL-1 family mediators in response to cutaneous photodamage. Photochem Photobiol. 2012;88:1111-25.

41. Lamkanfi M, Dixit VM. Inflammasomes and their roles in health and disease. Annu Rev Cell Dev Biol. 2012;28:137-61.

42. Goldbach-Mansky R. Immunology in clinic review series; focus on autoinflammatory diseases: Update on monogenic autoinflammatory diseases: The role of interleukin (IL)-1 and an emerging role for cytokines beyond IL-1. Clin Exp Immunol. 2012;167:391-404.

43. Kayagaki N, Warming S, Lamkanfi M, Vande Walle L, Louie S, Dong J, et al. Non-canonical inflammasome activation targets caspase-11. Nature. 2011;479:117-21.

44. Viganò E, Mortellaro A. Caspase-11: The driving factor for noncanonical inflammasomes. Eur J Immunol. 2013;43:2240-5.

45. Sutterwala FS, Haasken S, Cassel SL. Mechanism of NLRP3 inflammasome activation. Ann N Y Acad Sci. 2014;1319:82-95.

46. Gross O, Thomas CJ, Guarda G, Tschopp J. The inflammasome: An integrated view. Immunol Rev. 2011;243:136-51.

47. Guarda G, Dostert C, Staehli F, Cabalzar K, Castillo $\mathrm{R}$, Tardivel A, et al. T cells dampen innate immune responses through inhibition of NLRP1 and NLRP3 inflammasomes. Nature. 2009;460:269-73.

48. Hernández-Cuéllar E, Tsuchiya K, Hara H, Fang R, Sakai S, Kawamura I, et al. Cutting edge: Nitric oxide inhibits the $\mathrm{NLRP}_{3}$ inflammasome. J Immunol. 2012;189:5113-7.

49. Bauernfeind F, Rieger A, Schildberg FA, Knolle PA, Schmid-Burgk JL, Hornung V. NLRP3 inflammasome activity is negatively controlled by miR223. J Immunol. 2012;189:4175-81.

50. Aksentijevich I, Putnam CD, Remmers EF, Mueller JL, Le J, Kolodner RD, et al. The Clinical continuum of cryopyrinopathies novel CIAS1 mutations in North American patients and a new cryopyrin model. Arthritis Rheumatol (Hoboken, NJ). 2007;56:1273-85.

51. Razmara M, Srinivasula SM, Wang L, Poyet J, Geddes BJ, Distefano PS, et al. Mechanisms of signal transduction ECHANISMSprotein , a new CARD family member that regulates caspase- 1 activation and apoptosis. J Biol Chem. 2002;277:139528.
52. von Kampen O, Lipinski S, Till A, Martin SJ, Nietfeld W, Lehrach $\mathrm{H}$, et al. Caspase recruitment domain-containing protein 8 (CARD8) negatively regulates NOD2-mediated signaling. J Biol Chem. 2010;285:19921-6.

53. Ito S, Hara Y, Kubota T. CARD8 is a negative regulator for $N L R P_{3}$ inflammasome, but mutant NLRP3 in cryopyrin-associated periodic syndromes escapes the restriction. Arthritis Res Ther. 2014;16:111.

54. Rubartelli A. Redox control of $\mathrm{NLRP}_{3}$ inflammasome activation in health and disease. J Leukoc Biol. 2012;92:951-8.

55. Lugrin J, Rosenblatt-Velin N, Parapanov R, Liaudet L. The role of oxidative stress during inflammatory processes. Biol Chem. 2014;395:203-30.

56. Dinarrello CA. Overview of the interleukin-1 family of ligands and receptors. Immunology. 2013;25:389-93.

57. Dinarello CA. Immunological and inflammatory functions of the interleukin-1 family. Annu Rev Immunol. 2009;27:519-50.

58. Neill LAJO, Dinarello CA. The IL-1 receptor/tolllike receptor superfamily: Crucial receptors for inflammation and host defense. Immunol Today. 2000;21:206-9.

59. Agostini L, Martinon F, Burns K, Mcdermott MF, Hawkins PN, Boveresses $\mathrm{C}$, et al. NALP3 forms an IL-1 ${ }_{L}$ - processing inflammasome with increased activity in Muckle-Wells autoinflammatory disorder. Immunity. 2004;20:319-25.

6o. Vélez-Castrillón S, Camargo JF, Correa PA, Anaya J. Bases moleculares de la familia de la interleuquina-1. Rev Colomb Reumatol. 2004;11: 11-39.

61. Garlanda C, Riva F, Bonavita E, Mantovani A. Negative regulatory receptors of the IL-1 family. Semin Immunol. 2013;25:408-15.

62. Manzur F, Moneriz C. Canakinumab: un anticuerpo monoclonal prometedor en el tratamiento de enfermedades cardiovasculares. Rev Colomb Cardiol. 2012;20:33-9.

63. Dinarello CA, Novick D, Kim S, Kaplanski G. Interleukin-18 and IL-18 binding protein. Front Immunol. 2013;4:289.

64. Smith DE. The biological paths of IL-1 family members IL-18 and IL-33. J Leukoc Biol. 2011;89:383-92.

65. Brydges SD, Broderick L, McGeough MD, Pena CA, Mueller JL, Hoffman HM. Divergence of IL-1, IL-18, and cell death in NLRP3 inflammasomopathies. J Clin Invest. 2013;123:4695-705.

66. Kakkar R, Lee RT. The IL-33/ST2 pathway: Therapeutic target and novel biomarker. Nat Rev Drug Discov. 2008;7:827-40. 
67. Martin MU. Special aspects of interleukin-33 and the IL-33 receptor complex. Semin Immunol. Elsevier Ltd; 2013;25:449-57.

68. Jimenez-Treviño S, Ramos-Polo E. Tratamiento de los síndromes periódicos asociados a criopirina (CAPS). Med Clin. 2011;136(Sup.1):29-33.

69. Doherty TA, Brydges SD, Hoffman HM. Autoinflammation: Translating mechanism to therapy. J Leukoc Biol. 2011;90:37-47.

70. Bachove I, Chang C. Anakinra and related drugs targeting interleukin-1 in the treatment of cryopyrin- associated periodic syndromes. Open Access Rheumatol Res Rev. 2014;6:15-25.

71. Neven B, Marvillet I, Terrada C, Ferster A, Boddaert $\mathrm{N}$, Couloignier $\mathrm{V}$, et al. Long-term efficacy of the interleukin-1 receptor antagonist anakinra in ten patients with neonatal-onset multisystem inflammatory disease/chronic infantile neurologic, cutaneous, articular syndrome. Arthritis Rheum. 2010;62:258-67.

72. Federici S, Martini A, Gattorno M. The central role of anti-IL-1 blockade in the treatment of monogenic and multi-factorial autoinflammatory diseases. Front Immunol. 2013;4:351.

73. Kuemmerle-Deschner JB, Tyrrell PN, Koetter I, Wittkowski H, Bialkowski A, Tzaribachev N, et al. Efficacy and safety of anakinra therapy in pediatric and adult patients with the autoinflammatory Muckle-Wells syndrome. Arthritis Rheum. 2011;63:840-9.

74. Hawkins PN, Lachmann HJ, Aganna E, McDermott MF. Spectrum of clinical features in Muckle-Wells syndrome and response to anakinra. Arthritis Rheum. 2004;50:607-12.

75. Gelabert A, Jones J, Rubin BI, Kim HJ, Brewer C, et al. Neonatal-onset multisystem inflammatory disease responsive to interleukin-1 $\beta$ inhibition. $\mathrm{N}$ Engl J Med. 2006;581-92.

76. Lepore L, Paloni G, Caorsi R, Alessio M, Rigante D, Ruperto N, et al. Follow-up and quality of life of patients with cryopyrin-associated periodic syndromes treated with Anakinra. J Pediatr. 2010;157:310-5.e1.

77. Gillespie J, Mathews R, McDermott MF. Rilonacept in the management of cryopyrin-associated periodic syndromes (CAPS). J Inflamm Res. 2010;3:18.

78. Galeotti C, Koné-Paut I. Current options for the treatment of cryopyrin-associated periodic syndromes. Expert Opin Orphan Drugs. 2013;1:589-97.

79. Goldbach-Mansky R, Shroff SD, Wilson M, Snyder C, Plehn S, Barham B, et al. A pilot study to evaluate the safety and efficacy of the long-acting interleukin-1 inhibitor rilonacept (interleukin-1 TRAP) in patients with familial cold autoinflammatory syndrome. Arthritis Rheum. 2008;58:243242.

8o. Hoffman HM, Throne ML, Amar NJ, Sebai M, Kivitz AJ, Kavanaugh A, et al. Efficacy and safety of rilonacept (interleukin-1 Trap) in patients with cryopyrin-associated periodic syndromes: Results from two sequential placebo-controlled studies. Arthritis Rheum. 2008;58:2443-52.

81. Hoffman HM, Throne ML, Amar NJ, Cartwright RC, Kivitz AJ, Soo Y, et al. Long-term efficacy and safety profile of rilonacept in the treatment of cryopryin-associated periodic syndromes: Results of a 72-week open-label extension study. Clin Ther. 2012;34:2091-103.

82. Carné X. Canakinumab, un anticuerpo monoclonal frente a IL-1 $\beta$, con utilidad potencial en distintos procesos inflamatorios. Med Clin. 2011;136(Supl.1):34-7.

83. Dhimolea E. Interleukin-1 $\beta$ inhibitors for the treatment of cryopyrin-associated periodic syndrome. Appl Clin Genet. 2011;4:21-7.

84. Hachulla E, Quartier P, Gitton X, Widmer A, et al. Use of canakinumab in the cryopyrin- associated periodic syndrome. N Engl J Med. 2009;360:241625.

85. Koné-Paut I, Lachmann HJ, Kuemmerle-Deschner JB, Hachulla E, Leslie KS, Mouy R, et al. Sustained remission of symptoms and improved health-related quality of life in patients with cryopyrin-associated periodic syndrome treated with canakinumab: Results of a double-blind placebocontrolled randomized withdrawal study. Arthritis Res Ther. 2011;13:R202.

86. Ter Haar N, Lachmann H, Özen S, Woo P, Uziel Y, Modesto $\mathrm{C}$, et al. Treatment of autoinflammatory diseases: Results from the Eurofever Registry and a literature review. Ann Rheum Dis. 2013;72:67885.

87. Yokota S, Imagawa T, Nishikomori R, Takada H, Abrams K, Lheritier K, et al. Long-term safety and efficacy of canakinumab in cryopyrin-associated periodic syndrome: Results from an open-label, phase III pivotal study in Japanese patients.Clin Exp Rheumatol. 2017;35(Suppl.10):19-26. 